\title{
Tips and Techniques: A Modified Cross Leg Flap for Large Triangular Defects of the Foot and Ankle
}

\author{
by B. Jagannath Kamath, M.S. (Ortho) ${ }^{1} \rrbracket$, Thangam Varghese, Mch (Plastic Surgery), ${ }^{2}$ \\ Praveen Bhardwaj, M.S., (Ortho) $)^{3}$
}

The Foot \& Ankle Journal 1 (8): 5

An important technical modification in the conventional medial based cross leg flaps is described by the authors. The technique involves resurfacing large triangular defects in the medial lower leg, ankle and foot. This modification, by virtue of narrowing the pedicle, will help the surgeon to maximize the inset avoiding delaying of the flap or flap loss. Secondary defects created by raising the triangular flaps are amenable to considerable narrowing and leaving behind smaller defects that can easily be covered with a split thickness skin graft. Another advantage of the triangular flap is the primary inset portion of the flap provides more than 75-80 \% coverage to the injury site. This not only promotes early division of the flap without delay, but also enables the surgeon to maximize the secondary inset during the division of the flap and to cover the recipient area completely with the flap obviating the need for the split skin graft at the crucial triangular area of the original defect.

Key Words: Modified cross leg flap, medial based, triangular defect, foot and ankle, skin graft

Accepted: July 2008

Published: August 2008

This is an Open Access article distributed under the terms of the Creative Commons Attribution License. It permits unrestricted use, distribution, and reproduction in any medium, provided the original work is properly cited. @The Foot \& Ankle Journal (www.faoj.org)

C ross leg flaps have stood the test of time ever since its first description by Hamilton in 1854. It has always found an important place in the surgeon's armamentarium in reconstructive surgeries of the lower limb even in the era of micro and super-microsurgery. It is still a safe and viable option in primary and secondary care centers for the reconstructive surgery of the lower limb in situations such as larger distal defects in the leg and foot where distally based flaps from the ipsilateral leg calf are not feasible.

Address correspondence to: Dr. B. Jagannath Kamath. Jyothi Mansion, Opposite Prabhat Theatre, K. S. Rao Road, Mangalore, India. Pin- 575001. Phone: 91-0824-2440233; Mobile: 91-9845235747

E-mail: bjkamath@satyam.net.in

1 Professor of Orthopaedics, Kasturba Medical College, Mangalore, Karnataka, India.

${ }^{2}$ Professor of Plastic Surgery, Kasturba Medical College, Mangalore

Karnataka, India.

${ }^{3}$ Fellow in Hand and Reconstructive Microsurgery, Ganga Hospital, Coimbatore, India.
Even in tertiary care centers cross leg flaps is a viable procedure in failed free flap surgeries. This is quite relevant because the highest percentage of failure of free flaps is encountered in cases of resurfacing the traumatic defects of the distal leg and foot.

Like most of the proven procedures, cross leg flaps have also undergone refinement and modifications. With the advent of fasciocutaneous flaps described by Ponten in $1983^{1}$, the cross leg flaps have been raised safely and easily with 1:3 to 1:3.5 width to length ratio. Several authors have advocated routine use of external fixators in maintaining the position of cross leg and ease of nursing care and post operative wound management. 


\begin{tabular}{|c|l|l|l|l|c|c|}
\hline Case & Sex/Age & $\begin{array}{l}\text { Size of triangular defect } \\
\text { (cms) }\end{array}$ & $\begin{array}{l}\text { Division done after } \\
\text { (Days) }\end{array}$ & Complications & $\begin{array}{l}\text { Duration of follow } \\
\text { up (months) }\end{array}$ \\
\hline 1 & Male (29) & $18,21,13$ & 18 & None & 12 \\
\hline 2 & Male (8) & $12,16,9$ & 17 & None & 13 \\
\hline 3 & Female (14) & $16,19,11$ & 18 & None & 9 \\
\hline
\end{tabular}

Table 1 Demographics of three distinct cases describing the modified cross leg flap for large triangular defects of the foot and ankle.

This modification has been used both in children and adults with good results. Cross leg flaps have been used with their bases proximal, distal, medial and lateral depending on the size and shape of the recipient site and ease of planning in reverse. Some surgeons have used myocutaneous cross leg flaps to provide bulk, safety and to obliterate dead space in the recipient area. Conventional posterior tibial artery flap, sural artery flaps have been used as 'cross leg flaps'. Recently Pandey, et al., has used virtually the whole leg medially based fasciocutaneous cross leg flap with or without fibula for reconstructing large defects. Also, Bhattacharya, et al., ${ }^{3}$ have used distal perforator based cross leg flaps successfully for leg and foot defects with narrow pedicles and larger inset with greater patient comfort.

To the best of our knowledge, large triangular medially based cross leg flaps nourished by two or three posterior tibial perforators have not been described. These flaps are most suited in large triangular defects on the medial side of the foot and ankle, which are quite commonly encountered in children and adults following trauma. By virtue of creating a very narrow pedicle large triangular fasciocutaneous flaps involving different angiogomes can be raised to improve the perimeter or the circumference of the inset of the flap. This obviates the need for delaying of the flap before division. This is important because traumatic distal leg and foot defects leave behind a very poorly vascularised bed contributing very little to the neovascularisation of the cross leg flap. These defects demand a larger and more reliable inset preferably more than $70 \%$ of the original injury site or defect.

(C) The Foot \& Ankle Journal, 2008
If the shape of the defect is triangular it will be difficult to meet the requirement dimensions of the conventional broad based cross leg flaps. Medial fasciocutaneous cross leg flaps based on perforators can be used without altering the original shape of the wound. Unlike the conventional broad based rectangular cross leg flaps, the narrow based triangular or oval flaps permit considerable narrowing of the secondary wound and can be covered with split thickness skin graft. This also adds to the cosmetic benefits of the flap both at the donor and the recipient sites.

The authors recently had an opportunity to use cross leg flaps with a technical modification to suit the need of resurfacing triangular defects of the lower leg after the trauma. Three patients with large triangular medial defects over the lower leg, ankle and foot were treated in our surgery department between December 2004 and January 2006. (Table 1)

All three defects were covered with a medially based narrow pedicled triangular cross leg flap based on 2-3 adjacent posterior tibial perforators about 1-2 $\mathrm{cm}$ from the medial border of the tibia in its middle third. The perforators are identified preoperatively by a hand held Doppler. No attempt is made to isolate or skeletonize the perforator and hence by definition these flaps could be termed as perforator plus flaps as described by Sharma, et al. ${ }^{4}$ Flaps are raised as fasciocutaneous flaps involving not only posterolateral but also anterior compartmental tissue. 
The secondary wound created is considerably reduced as the triangular edges are primarily sutured using the visco-elastic property of the calf skin. The rest of the donor site is covered with a split thickness skin graft and the larger, triangular flap is used to cover the injured site. The inset region provides more than $75-80 \%$ coverage to the perimeter of the injury site in all three cases. The cross-legged position is maintained be external fixators and the flap is divided at the end of $2 \frac{1}{2}$ weeks. All three defects healed primarily providing stable skin cover.

An illustrative example using this triangular technique is described in the following figures.

\section{Photo Description of Technique}

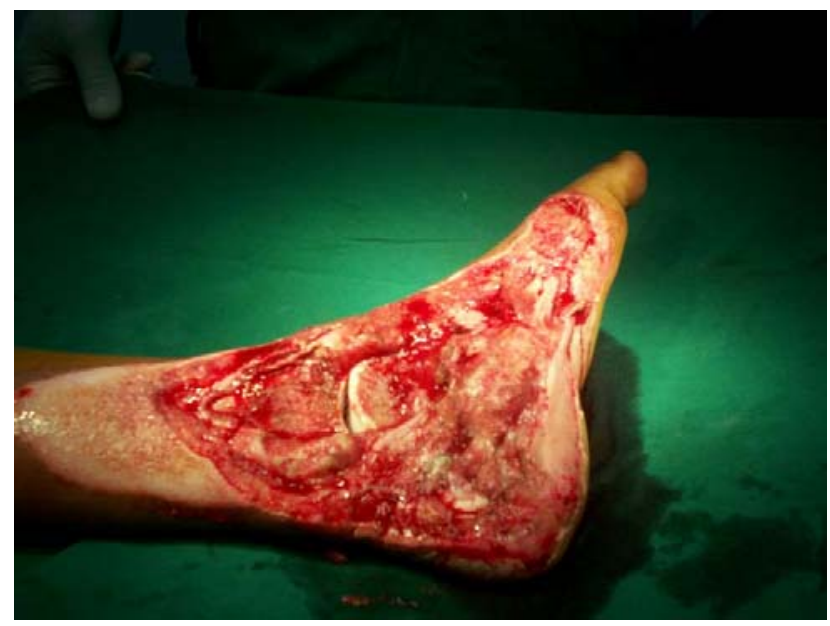

Figure 1 Preoperative photograph showing the traumatic defect over the medial aspect of the foot with exposed bone.

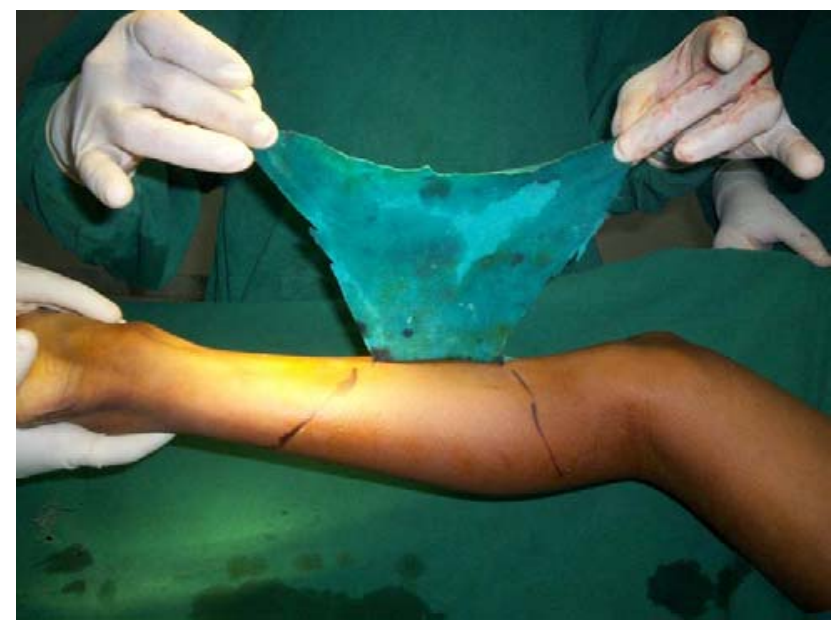

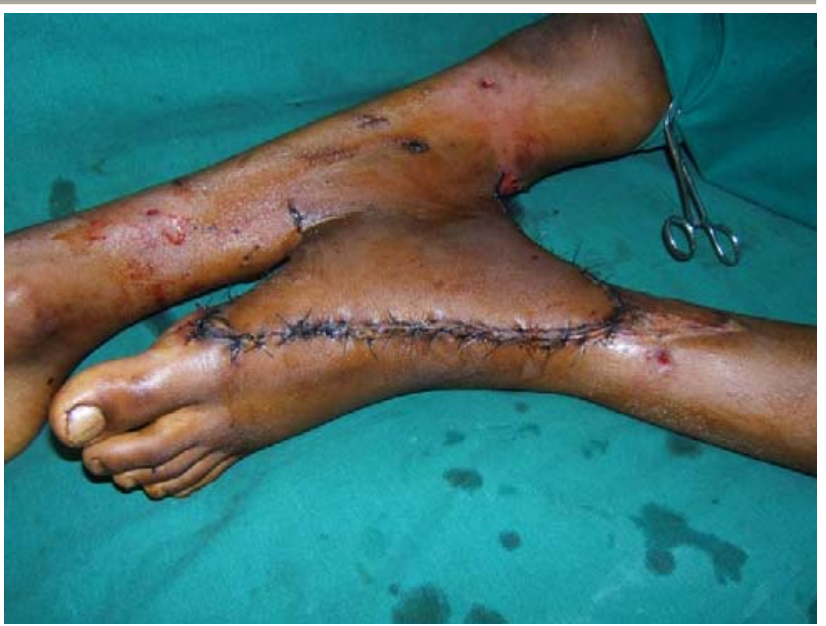

Figure 3 Flap with primary inset providing more than $75-80 \%$ coverage to the perimeter of the injury site.

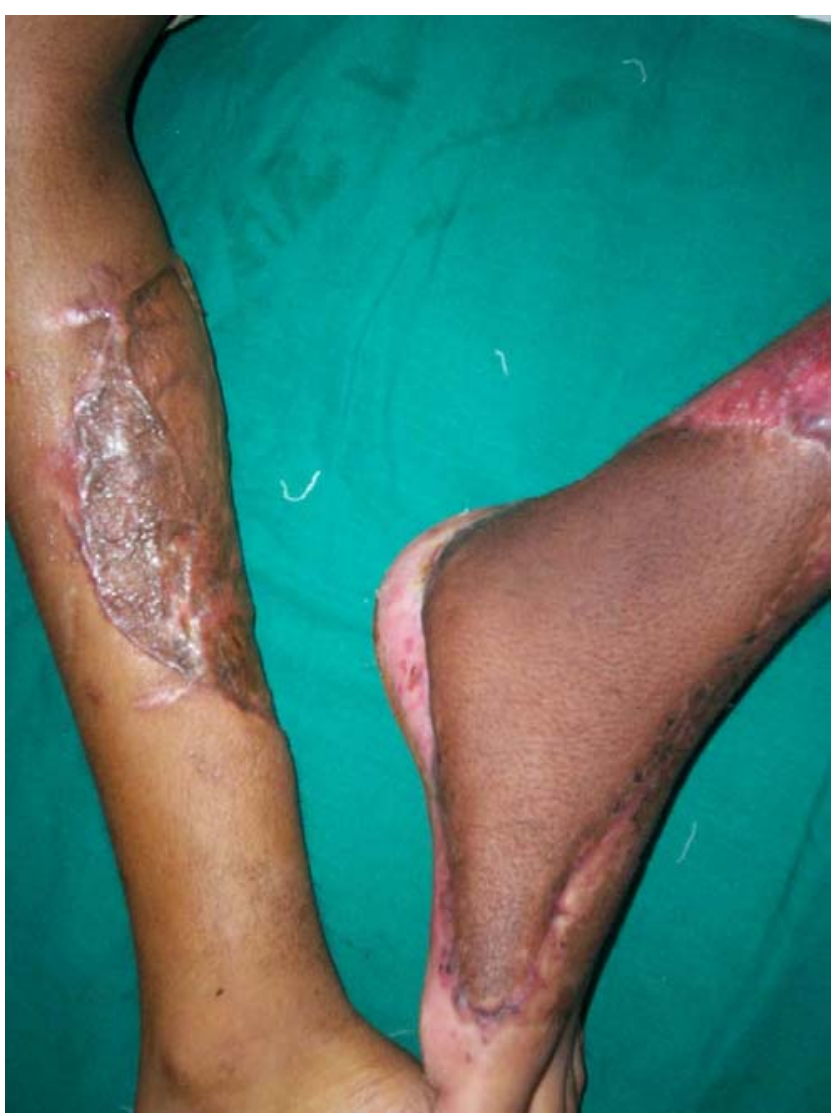

Figure 4 Follow up result, showing stable skin cover.

Figure 2 Picture showing the 'planning in reverse'. 


\section{References}

1. Ponten B. The fasciocutaneous flap. Its use in soft tissue defects of lower leg. Br. J Plast Surg. 34: 215, 1981.

2. Pande S, Kohli JS, Arora S, Bajaj SP. The osseofasciocutaneous flap: a new method to transfer fibula along with a sufficient amount of skin. Br. J Plast Surg. 55: 312-319, 2002.

3. Bhattacharya V, Reddy GR. Distal perforator based cross leg flaps for leg and foot defects. Indian J Plast Surg. 38(1): 18-21, 2005.

4. Sharma RK, Mehrotra S, Nanda V. The perforator "plus" flap: a simple nomenclature for locoregional perforator-based flaps. Plast Reconstr Surg. 116(6): 1838-9, 2005. 